\title{
KRISENMANAGEMENT AUF ÖSTERREICHISCH
}

\author{
Liebe Kolleginnen und Kollegen!
}

Wie soll dieses Vorwort nicht Bezug nehmen auf die ,Krise", in die uns die Coronapandemie gestürzt hat? Wobei abgesehen von finanziellen Einschränkungen und ganz abgesehen von Jobverlust und anderen Existenzängsten, sind wir wirklich schon in der Krise, wenn wir ein paar Wochen lang leisere Töne anschlagen? Wenn wir uns mehr um uns selbst und unsere Familie kümmern, als um die Außenwelt? Wenn wir künstlich leiser treten müssen/dürfen und unser Stresslevel sich halbiert (Multitasking Homeoffice\&Homeschooling - Eltern kleiner Kinder ausgenommen)? Ist das nicht der Zustand, den jeder von uns für die Adventzeit anstrebt und keiner je schafft? Ist diese Langsamkeit und das Rückbesinnen auf das Wesentliche nicht etwas, das aus Sicht der Chinesischen Medizin etwas ist, das wir unseren Patienten durchaus verschreiben? Wir wissen, dass das Wei Qi - unsere Abwehrenergie nicht nur vor Infektionen aller Art schützt, sondern uns vielmehr auch vor dem Eindringen anderer krankmachender Faktoren wie negativer Energien, Emotionen usw. schützt. So ist ein kurzfristiger Rückzug von dem extremen Leben im Außen sicherlich hilfreich, um unser WeiQi seine Arbeit machen zu lassen, nämlich unser Immunsystem in diesen Zeiten aufrecht zu erhalten, um nicht so anfällig für das Virus zu sein.

Was ist das Resümee für die OGKA dieser schwierigen Zeit?

- Fazit 1:Wir haben sie gut überstanden, indem wir ganz gemäß dem chinesischen Rat „flexibel wie Bambus“ waren und so gut mit Änderungen der Kursgegebenheiten, aber auch Arbeitsbedingungen umgehen konnten.
- Fazit 2:Wir haben Telekommunikation schätzen gelernt - Dienstagsbesprechungen sind auch via Skype produktiv und man muss sich keine Gedanken um das Outfit machen, zumindest was Hosen betrifft.

- Fazit 3:Wir haben auf Onlinekurse umgestellt, um unsere Kurse durchführen zu können, was ungewohnt war und das Erlernen neuer Fähigkeiten bedeutet, was uns aber sehr schnell in die Zukunft des Unterrichtens katapultiert hat. An dieser Stelle herzlichen Dank an Dr. Wolfgang Jan, der uns an diese neue Technik heranführt und viel Zeit und Herzblut in das Projekt Webinare und Videos investiert hat.

- Fazit 4 (mein Persönliches): Wenn die von der Politik beschworene „neue Normalität“ bedeutet, dass wir gesellschaftlich gesehen zurück in den Zustand vor der Krise gelangen, dann möchte ich dort nicht mehr hin. Wir haben etwas geschafft, schwierige Situationen gemeistert, Resilienz gezeigt und uns als Einzelperson, aber auch als Gesellschaft weiterentwickelt. Wir haben die leisen Töne kennen- und schätzen gelernt, und wenn wir wirklich schlau sind, spielen wir von nun an nicht nur fortissimo in unserem Leben, sondern nutzen unsere gesamtes Repertoire aus.

In diesem Sinne, ein Hoch auf die neue Achtsamkeit, und dass sie uns erhalten bleiben möge!

Ihre

O. Krammer-Pojer 